\title{
Synthesis of porphyrin- graphene oxide nanocomposite for an optical chemical sensor application
}

\author{
Rahmatollah Rahimi*, Rouholah Zare - Dorabei*, Asgar Koohi, Solmaz Zargari \\ Department of Chemistry, Iran University of Science and Technology, Tehran 16846-13114, \\ Iran
}

\begin{abstract}
A specific and sensitive optical chemical sensor (optode) was fabricated for the determination of mercury ions. The optode was prepared by graphene oxide-porphyrin composite. The graphene oxide-porphyrin composite was synthesized and characterized by field emission scanning electron microscopy (FE-SEM), UV-Vis and Fourier transform infrared (FT-IR) spectroscopic techniques. The various experimental parameters such as $\mathrm{pH}$ of aqueous solution of $\mathrm{Hg}$ (II) and content of the THPP as well as the grapheme oxide have been optimized. This optode exhibited a linear range of $6.0 \times 10^{-5}$ to $6.0 \times 10^{-9} \mathrm{~mol} . \mathrm{L}^{-1} \mathrm{Hg}$ (II) with a detection limit of $3.2 \times 10^{-9} \mathrm{~mol} . \mathrm{L}^{-1}$ and a response time of $\sim 210 \mathrm{~s}$.
\end{abstract}

\section{Keywords:}

Optical sensor, Graphene oxide nanosheets, Porphyrin, Mercury ions, Spectrophotometry UV-Vis.

*Corresponding authors

E-mail address: rahimi_rah@iust.ac.ir zaredorabei@iust.ac.ir 


\section{Introduction}

Heavy metal pollution due to the indiscriminate disposal of wastewater is a worldwide environment concern. Wastewaters from many industries such as metallurgical, mining, chemical manufacturing, and battery manufacturing industries contain many kinds of toxic heavy metal ions. Mercury is a highly toxic heavy metal that causes human health problems and environmental contamination, and is also more toxic even from lead and arsenic. This metal represents a major toxicity to microorganisms and environment even in low concentrations. Mercury triggers several serious disorders for humans including allergic reactions and brain and neurological damage. If ingested by a pregnant woman, it can cause developmental delays in children. Therefore, the detection of very little amounts of mercury is extraordinarily important [1-4].

Design of control systems such as optical chemical sensors for determination of mercury in very low concentrations in water samples and rivers can be very useful and effective in the control and remove pollutants from the environment $[1,5]$. In recent years, extensive research is allocated into optical chemical sensors. Optical chemical sensors used in different contexts such as environmental, clinical and industrial analysis. The use of optical chemical sensors, nutrients is very important particularly for the measurement of trace amounts of heavy metal ions in environmental samples. The application of optical chemical sensors is highly regarded especially for the determination of trace amounts of heavy metal ions in environmental samples, a variety of water and food [6-7].

Porphyrins have been studied as probe molecules in different materials and their application has been examined as detector for chemical sensors. Porphyrins are sensitive to metal ions. Nitrogen atoms in the structure of porphyrin ring is located inward, and with their only electron pairs can act as a strong ligand, and they keep the metal ions in the center and the formation a complexes [8-14]. Choosing a proper substrate and detector stabilizer, are a very 
important issue as another part of the membrane components in optical sensors. A proper grounds should be suitable functional groups to bind and detector stabilize on the plastic or glass fulcrum. Graphene Oxide with carboxyl functional groups, hydroxyl and epoxy on itself carbon surface, has been studied as a substrate and important factor to bind and stabilize detector on the Fulcrum [15-17]. Therefore, in this work, a specific and sensitive optical chemical sensor based graphene oxide-porphyrin composite was fabricated for the determination of mercury ions.

\section{Experimental}

\section{1 . Chemicals}

All reagents were prepared from analytical reagent grade chemicals supplied from Merck (Darmstadt, Germany), except $\mathrm{HgCl}_{2}$ which was obtained from Aldrich. The $10^{-3} \mathrm{M}$ mercury standard stock solution was prepared by dissolving $0.0811 \mathrm{~g}$ of $\mathrm{HgCl}_{2}$ in a $250 \mathrm{~mL}$ volumetric flask and diluting to the mark with distilled water. Lower concentrations were prepared by serial dilution of the stock solution with phosphate buffer, $\mathrm{pH} 7.5$ Universal buffer solutions $(0.1 \mathrm{M})$ were prepared from phosphoric acid solutions and sodium hydroxide solutions and adjusting $\mathrm{pH}$ to the desired value $(0.08 \mathrm{M})$. The final $\mathrm{pH}$ was adjusted with the addition of a sodium hydroxide.

\section{2 . Synthesis of GO-THPP}

\subsubsection{Synthesis of THPP}

Tetrakis (4-hydroxyphenyl) porphyrin (THPP) was prepared using a modification of A. D. Adler-f. R. Longo method [18]. Briefly in a typical reaction, $80 \mathrm{~mL}$ of propionic acid was loaded in a $250 \mathrm{~mL}$ round-bottomed flask and refluxed for $0.5 \mathrm{~h}$. Then $1.146 \mathrm{~g}$ 4Hydroxybenzaldehyde dissolved in $10 \mathrm{~mL}$ of propionic acid are added. After about 15 
minutes the amount of $6.0 \mathrm{~g}$ of fresh distilled pyrrole was slowly added into the solution. After 45 min the mixture was placed at room temperature to precipitate formed. The dark purple product was filtered and washed thoroughly with ethanol until the filtrate became clear.

\subsubsection{Synthesis of graphene oxide nanosheets (GO)}

Graphene oxide was prepared using a modification of Hummers and Offeman's method [19, 20]. Briefly in a typical reaction, $1 \mathrm{~g}$ graphite, $1 \mathrm{~g} \mathrm{NaNO}_{3}$, and $46 \mathrm{~mL} \mathrm{H}_{2} \mathrm{SO}_{4}$ were stirred together in an ice bath. $\mathrm{KMnO}_{4}(8 \mathrm{~g})$ was slowly added while stirring, and the rate of addition was controlled to prevent the mixture temperature from exceeding $20{ }^{\circ} \mathrm{C}$. The mixture was then transferred to a $35{ }^{\circ} \mathrm{C}$ water bath and stirred for about $1 \mathrm{~h}$, forming a thick paste. Subsequently, $80 \mathrm{~mL}$ de-ionized water was added gradually and the temperature was raised to $90{ }^{\circ} \mathrm{C}$. The mixture was further treated with $10 \mathrm{~mL} 30 \% \mathrm{H}_{2} \mathrm{O}_{2}$ solution. The solution was then filtered and washed with de-ionized water until the $\mathrm{pH}$ was 6 and dried at $65{ }^{\circ} \mathrm{C}$ under vacuum.

\subsubsection{Synthesis of GO-COCl}

Briefly in a typical reaction, $0.5 \mathrm{~g} \mathrm{GO}-\mathrm{COOH}$ was suspended in $30 \mathrm{~mL} \mathrm{SOCl} 2$ and $5 \mathrm{~mL}$ of DMF. The mixture was refluxed for $24 \mathrm{~h}$ at $70^{\circ} \mathrm{C}$ under nitrogen atmosphere. The resultant solution was filtered and washed with anhydrous tetrahydrofuran (THF) and dried under vacuum 


\subsubsection{Synthesis of covalently attached porphyrin graphene oxide hybrids (GO-THPP)}

Briefly in a typical reaction, a mixture of $30 \mathrm{mg} \mathrm{GO}-\mathrm{COCl}$ and $60 \mathrm{mg}$ THPP were taken in a $100 \mathrm{~mL}$ round bottom flask and $3 \mathrm{~mL}$ of triethylamine and $15 \mathrm{~mL}$ of DMF were added and heated to $80^{\circ} \mathrm{C}$ for $72 \mathrm{~h}$ under a nitrogen atmosphere. After the reaction, the solution was cooled to room temperature, and then poured into $250 \mathrm{~mL}$ diethyl ether to precipitate the product. The precipitate was collected by centrifuging at $8000 \mathrm{rpm}$ for $30 \mathrm{~min}$. The supernatant which contained dissolved THPP was discarded and the precipitate was washed thoroughly. After adding another $100 \mathrm{~mL}$ of diethyl ether, the mixture was sonicated for 5 min and then centrifuged at $8000 \mathrm{rpm}$ for $30 \mathrm{~min}$ to collect the GO-THPP. Finally, the precipitate was washed with $\mathrm{CHCl}_{3}$ five times following the above procedure.

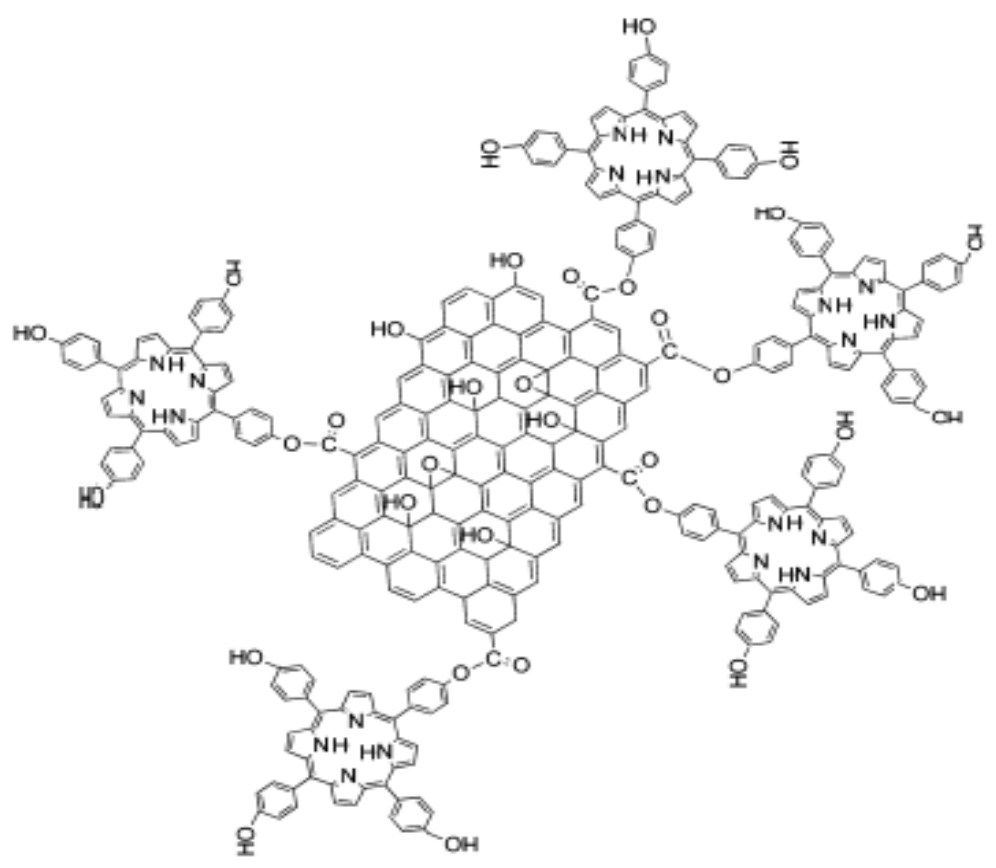

Fig. 1. The schematic illustration of GO-THPP 


\subsection{Structural and spectroscopic characterization of GO-THPP}

The FTIR spectra were recorded using $\mathrm{KBr}$ plates in the range $500-4000 \mathrm{~cm}$ using a Nicolet 6700 FT-IR spectrometer. Fig. 2 shows the typical FTIR spectrum obtained for our graphite oxide material. The most characteristic features are the broad, intense band at $3430 \mathrm{~cm}^{-1}(\mathrm{O}-$ $\mathrm{H}$ stretching vibrations) and the bands at $1725 \mathrm{~cm}^{-1}(\mathrm{C}=\mathrm{O}$ stretching vibrations from carbonyl and carboxylic groups), $1639 \mathrm{~cm}^{-1}$ (skeletal vibrations from unoxidized graphitic domains), $1380 \mathrm{~cm}^{-1}$ (C-OH stretching vibrations), and $1027 \mathrm{~cm}^{-1}$ (C-O stretching vibrations). The appearance of the peaks at around $2900 \mathrm{~cm}^{-1}$ is ascribed to the aromatic stretching vibrations of $\mathrm{C}-\mathrm{H}$ bonds of $\mathrm{GO}$. After covalent functionalization with porphyrins, a new peak appears at $\sim 1582 \mathrm{~cm}^{-1}$ corresponding to the $\mathrm{C}=\mathrm{C}$ vibrations of porphyrins and the peak of the $\mathrm{C}-\mathrm{O}$ stretching vibration shifts to $1108 \mathrm{~cm}^{-1}$, and broadens. The peak present at $\sim 1707 \mathrm{~cm}^{-1}$ is assigned to the bending vibration of the $\mathrm{C}=\mathrm{N}$ of the porphyrin ring. The disappearance of the peak at $1380 \mathrm{~cm}^{-1}$ clearly indicates that in graphene oxide-porphyrin composites, the porphyrin molecules are covalently bonded to the graphene oxide via carboxylic acid linkage.

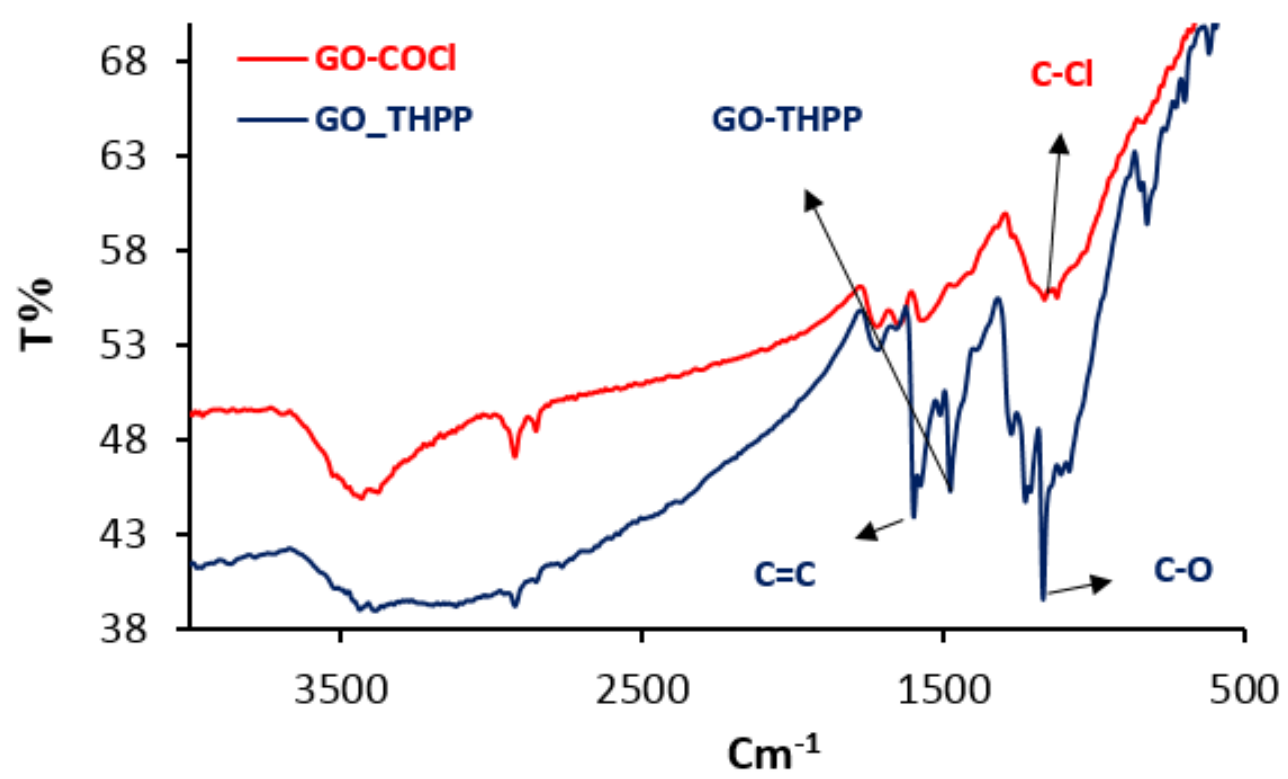

Fig. 2. FT-IR spectrum of graphene oxide and porphyrin-GO composites 
The SEM image (Figure 3) shows that few layered graphene oxides are formed, although the SEM image does not estimate the layer numbers of the graphene oxide nanosheets exactly. Pure graphite exhibits ordered flakes of a $4-5 \mu \mathrm{m}$ range. The scanning electron micrograph for the GO-porphyrin hybrid materials (Fig. $3 \mathrm{~B}$ ) demonstrates that a homogeneous system with a micrometer order of magnitude was obtained. On functionalization, GO exhibits a three-dimensional network of randomly oriented sheet-like structures with a wrinkled texture and hierarchical pores with a wide size distribution
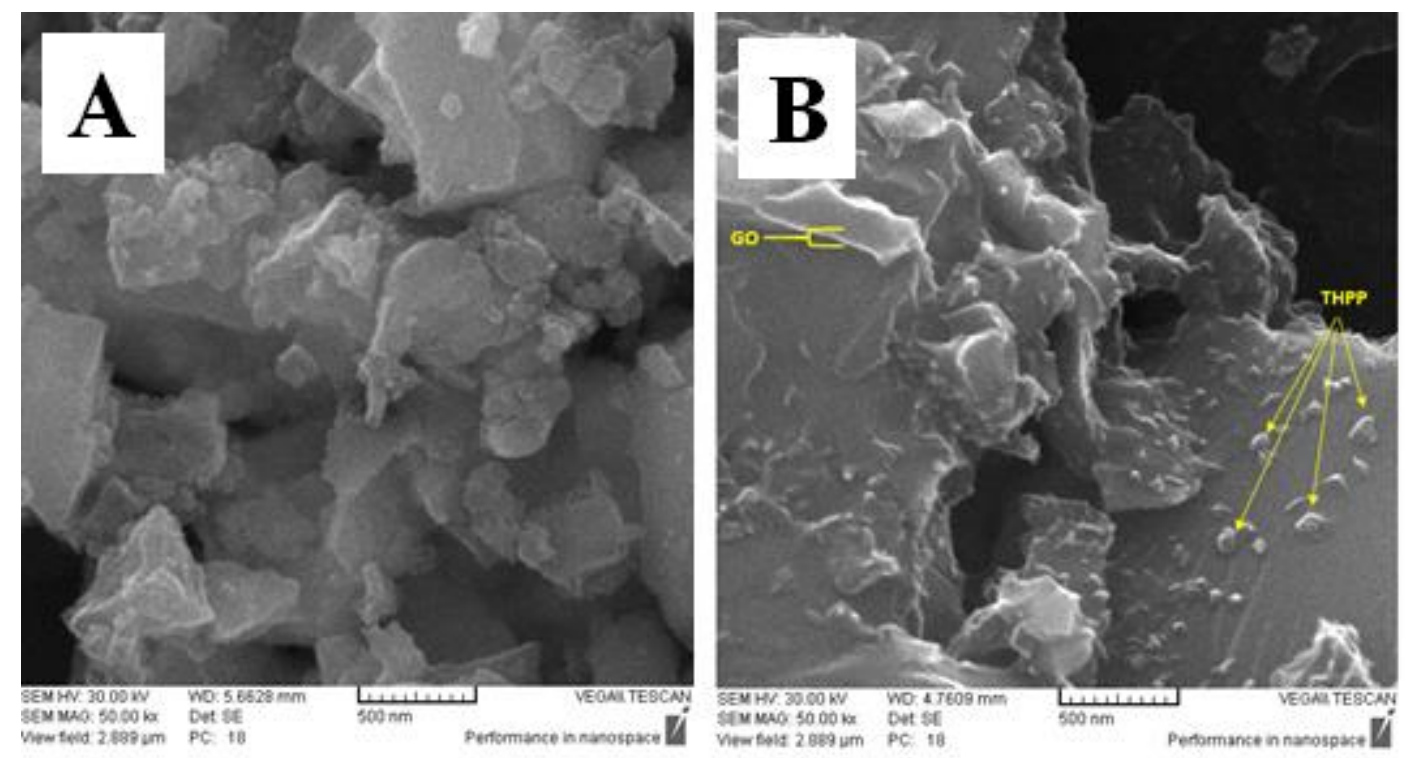

Fig. 3. SEM images of A) graphene oxide nanosheets and B) graphene oxide-porphyrin composites.

The optical absorption measurements were carried out by UV-Visible spectrometry. Fig. 4 shows optical absorption spectra of graphene oxide-porphyrin composites which agrees with the literature value. 


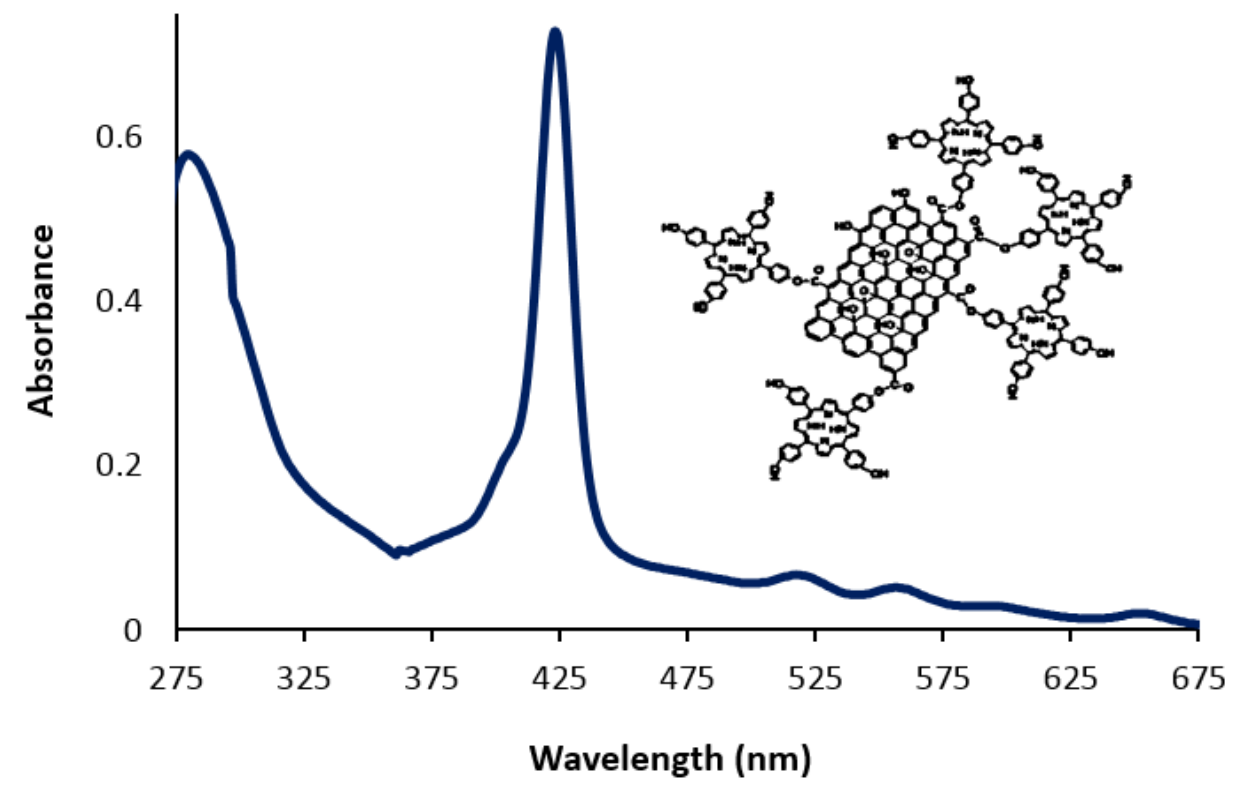

Fig. 4. UV/Vis spectrum of graphene oxide-porphyrin composites in DMF.

\subsection{Membrane preparation}

A mixture of $0.6 \mathrm{mg}$ graphene oxide-porphyrin composites, was dissolved in $1.0 \mathrm{~mL}$ of DMF. The membrane solution was homogenized with a magnetic stirrer for $15 \mathrm{~min}$. A Plexiglas slides with $9 \mathrm{~mm} \times 40 \mathrm{~mm}$ dimensions were cut to fit into standard spectrophotometer cells. The slides were cleaned with ethanol, then water and finally dried in an oven at $70{ }^{\circ} \mathrm{C}$. The membranes were cost by pipetting $10 \mu \mathrm{L}$ of the membrane solution onto a Plexiglas slide and spread it by a spin coater was deposit uniform thin films to flat substrates.

\subsection{Measurement procedure}

The membrane was conditioned by inserting it into a cell including $3 \mathrm{~mL}$ of phosphate buffer $(\mathrm{pH} 7.5)$. After 5 min the membrane absorbance was measured at $426 \mathrm{~nm}$. Then, the cell was filled with the $\mathrm{Hg}$ (II) standard solution and after $210 \mathrm{~s}$ its absorbance was measured in the same wavelength 


\section{Results and discussion}

\subsection{Principle of the operation}

Tetrakis (4-hydroxyphenyl) porphyrin (THPP) contains a nitrogen donor atom which could form internal bonds with soft metal ions such as mercury (II). THPP has high affinity to make a complex with mercury (II) ions. Mercury (II) ions form a complex with the ligand when the organic membrane contacts with the aqueous solution; therefore, the following ion-exchange reaction takes place:

$\mathrm{H}_{2}(\mathrm{~L})_{(\mathrm{m})}+\mathrm{Hg}^{2+}{ }_{(\mathrm{aq})} \leftrightarrow(\mathrm{L}) \mathrm{Hg}_{(\mathrm{m})}+2 \mathrm{H}^{+}{ }_{(\mathrm{aq})}$

In this equation, ' $\mathrm{L}$ ' is the Ligand. It can be seen that by the addition of mercury ions into the aqueous solution, the chromoionophore in the organic membrane is more deprotonated. Fig. 5 shows the absorption spectra of the optode with different concentrations of $\mathrm{Hg}$ (II) in the range $1.0 \times 10^{-14}$ to $1.0 \times 10^{-3} \mathrm{~mol} \mathrm{~L}^{-1}$.

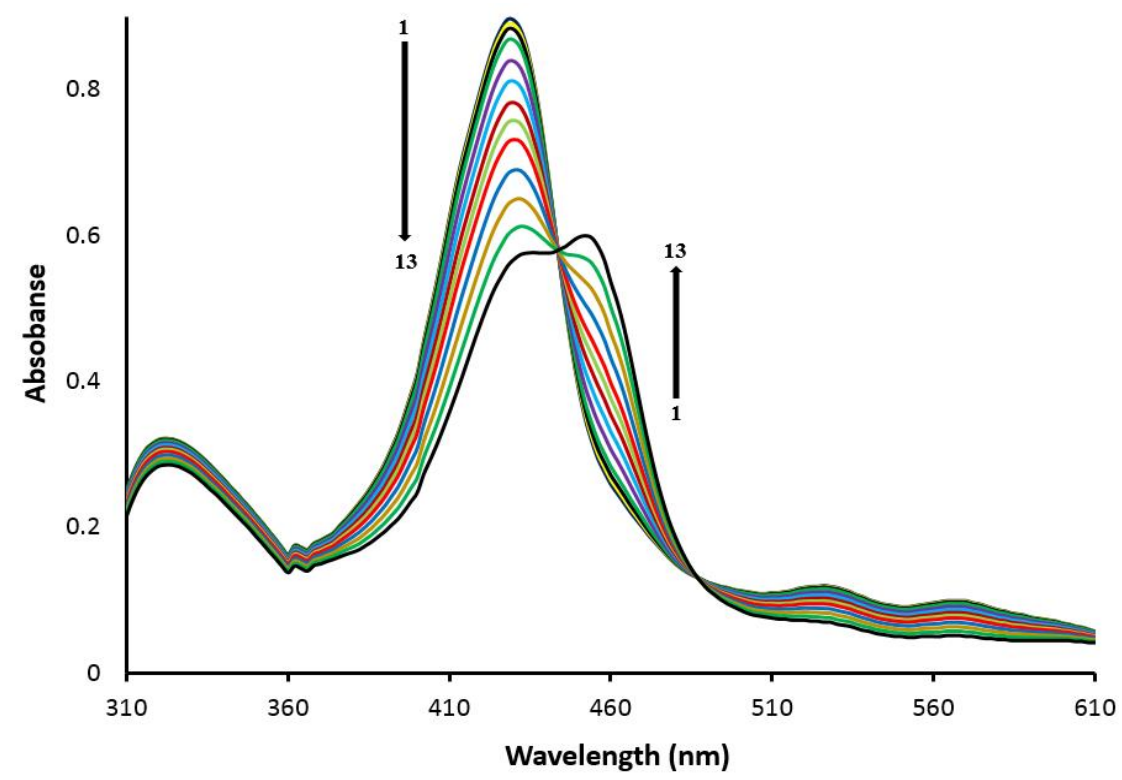

Fig. 5. Absorption spectra of the optical sensor in phosphate buffer solution (pH

7.5)containing different concentrations of $\mathrm{Hg}(\mathrm{II})$ as: 1) Blank solution (buffer); 2) $1.0 \times 10^{-14}$; 3) $1.0 \times 10^{-13}$; 4) $1.0 \times 10^{-12}$; 5) $1.0 \times 10^{-11}$; 6) $1.0 \times 10^{-10}$; 7) $1.0 \times 10^{-9}$; 8) $1.0 \times 10^{-8}$; 9) $1.0 \times$ $10^{-7}$; 10) $1.0 \times 10^{-6}$; 11) $1.0 \times 10^{-5}$; 12) $1.0 \times 10^{-4}$; 13) $1.0 \times 10^{-3}$ mol.L $\mathrm{L}^{-1} \mathrm{Hg}(\mathrm{II})$. 


\section{Conclusion}

In this work a new composites was synthesized based on the tetrakis (4-hydroxyphenyl) porphyrin (THPP) stabilized with graphene oxide as compound for the designs optical chemical sensor. The optode described in this work is easily prepared and provides a simple and inexpensive means for the determination of ultra-trace amounts of $\mathrm{Hg}$ (II) ions. Based on the results, it is clear that the determination of $\mathrm{Hg}$ (II) ions with optode prepared from graphene oxide-porphyrin composites were a selective and sensitive methods. The amount of mercury was measured in different water samples by the optode and also by ICP method. The results confirm that there was not any significant difference between the results.

\section{References}

[1] A. R. Firooz, M. Movahedi A. A. Ensafi, "Selective and sensitive optical chemical sensor for the determination of $\mathrm{Hg}$ (II) ions based on tetrathia-12-crown-4 and chromoionophore I", Sensors and Actuators B, 171-172, 492-498, (2012).

[2] Y. Yang, J. Jiang, G. Shen, R.Yu, "An optical sensor for mercury ion based on the fluorescence quenching of tetra (p-dimethylaminophenyl) porphyrin", Analytical Chemical Acta, 636, 83-88, (2009).

[3] K. Alizadeh ,R. Parooi ,P. Hashemi ,B. Rezaei, M. R. Ganjali, "A new Schiff’s base ligand immobilized agarose membrane optical sensor for selective monitoring of mercury ion", Journal of Hazardous Materials, 186, 1794-1800, (2011).

[4] A. Oehmen, D. Vergel, J. Fradinho, M. A. M. Reis, "Mercury removal from water streams through the ion exchange membrane bioreactor concept", Journal of Hazardous Materials, 264, 65-70, (2014). 
[5] A. R. Firooz, A. A. Ensafi, K. Karimi, R. Khalifeh, " Specific sensing of mercury(II) ions by an optical sensor based on a recently synthesized ionophore", Sensors and Actuators B, 185, 84-90, (2013).

[6] J. Janata, A. Bezegh, "Chemical Sensors", Anal. Chem, 60, 62R-74R, (1988).

[7] P. Gründler, "Chemical Sensors", Springer-Verlag Berlin Heidelberg, (2007).

[8] R. Yang, K. Li, K. Wang, F. Liu, N. Li, F. Zhao, "Cyclodextrin-porphyrin supramolecular sensitizer for mercury(II) ion", Analytical Chemical Acta, 469, 285-293, (2002).

[9] W. H. Chana, R. H. Yang, K. M. Wang, "Development of a mercury ion-selective optical sensor based on fluorescence quenching of 5, 10, 15, 20-tetraphenylporphyrin", Analytical Chemical Acta, 444, 261-269, (2001).

[10] P. Kumar, Y.B. Shim, "A novel Mg (II)-selective sensor based on 5, 10, 15, 20-tetrakis (2-furyl)-21, 23-dithiaporphyrin as an electroactive material", Journal of Electroanalytical Chemistry, 661, 25-30, (2011).

[11] I. Leray, M. C. Vernieres, R. L. Saibi, C. B. Charreton, J. Faure, "Porphyrins as probe molecules in the detection of gaseous pollutants I: Diffusion of pyddine in polystyrene films containing zinc- tetraphenyl porphyrin", Sensors and Actuators B, 37, 67-74, (1996).

[12] H. K. Lee, K. Song, H. R. Seo, Y. K. Choi, S. Jeon, "Lead(II) selective electrodes based on tetrakis(2-hydroxy-1-naphthyl)porphyrins: the effect of atropisomers", Sensors and Actuators B, 99, 323-329, (2004).

[13] K. Kilian, K. Pyrzynska, "Spectrophotometric study of Cd(II), $\mathrm{Pb}(\mathrm{II}), \mathrm{Hg}(\mathrm{II})$ and $\mathrm{Zn}$ (II) complexes with 5,10,15,20-tetrakis(4-carboxylphenyl) porphyrin", Talanta, 60, 669-678, (2003).

[14] M. Biesaga, K. Pyrzynska, M. Trojanowicz, "Porphyrins in analytical chemistry. A review", Talanta, 51, 209-224, (2000). 
[15] G. Zhao, J. Li, X. Ren, C. Chen, X. Wang, "Few-Layered Graphene Oxide Nanosheets As Superior Sorbents for Heavy Metal Ion Pollution Management", Environ. Sci. Technol, 45, 10454-10462, (2011).

[16] Q. Xiang, J. Yu, M. Jaroniec, "Graphene-based semiconductor photocatalysts", Chem. Soc. Rev, 41, 782-796, (2012).

[17] V. Georgakilas, M. Otyepka, A. B. Bourlinos, V. Chandra, N. Kim, K. C. Kemp, P. Hobza, R. Zboril, K. S. Kim, " Functionalization of Graphene: Covalent and Non-Covalent Approaches, Derivatives and Applications", Chem. Rev, (2012).

[18] S. Shanmugathasan, C. Edwards, R. W. Boyle, "Advances in Modern Synthetic Porphyrin Chemistry", Tetrahedron, 56, 1025-1046, (2000).

[19] M. B. M. Krishna, N. Venkatramaiah, R. Venkatesan, D. N. Rao, "Synthesis and structural, spectroscopic and nonlinear optical measurements of graphene oxide and its composites with metal and metal free porphyrins", J. Mater. Chem, 22, 3059-3068, (2012).

[20] W. S. Hummers, R.E. Offeman, "Synthesis and characterization of graphene oxide", J. Am. Chem. Soc, 80, 1339-1339, (1958). 